\title{
Primary and booster vaccination in Latin American children with a DTPw-HBV/Hib combination: a randomized controlled trial
}

\author{
Felix Espinoza', Miguel Tregnaghi ${ }^{2}$, Angela Gentile ${ }^{3}$, Katia Abarca $^{4}$, Javier Casellas ${ }^{5}$, Alix Collard ${ }^{5}$, Inge Lefevre ${ }^{5}$,
} Jeanne-Marie Jacquet ${ }^{5^{*}}$

\begin{abstract}
Background: Diphtheria-tetanus-whole-cell pertussis (DTPw)-based combination vaccines are an attractive option to rapidly achieve high coverage and protection against other important pathogens, such as hepatitis B virus (HBV) and Haemophilus influenzae type B (Hib). To ensure adequate antigen supply, GlaxoSmithKline Biologicals has introduced a new DTPw antigen source and developed a new DTPw-HBV/Hib combination vaccine containing a reduced amount of Hib polyribosylribitol phosphate (PRP). This study was undertaken to compare the immunogenicity and reactogenicity of this new DTPw-HBV/Hib vaccine with a licensed DTPw-HBV/Hib vaccine (Tritanrix $\left.{ }^{\text {TM}}-\mathrm{HBV} / \mathrm{Hib}\right)$.

Methods: This was a randomized, partially-blind, multicenter study in three countries in Latin America (Argentina, Chile and Nicaragua). Healthy children received either the new DTPw-HBV/Hib vaccine (1 of 3 lots; $n=439 ;$ double-blind) or Tritanrix ${ }^{\mathrm{TM}}$-HBV/Hib ( $\mathrm{n}=146$; single-blind) co-administered with oral poliovirus vaccine (OPV) at 2 , 4 and 6 months, with a booster dose at 18-24 months.

Results: One month after the end of the 3-dose primary vaccination course, the new DTPW-HBV/Hib vaccine was non-inferior to Tritanrix ${ }^{\mathrm{T}}$-HBV/Hib in terms of seroprotection/vaccine response rates for all component antigens; $\geq 97.3 \%$ and $\geq 93.9 \%$ of subjects in the two groups, respectively, had seroprotective levels of antibodies against diphtheria, tetanus, hepatitis B and Hib and a vaccine response to the pertussis component. Persistence of antibodies against all vaccine antigens was comparable between groups, with marked increases in all antibody concentrations after booster administration in both groups. Both vaccines were generally well-tolerated as primary and booster doses.
\end{abstract}

Conclusions: Results confirm the suitability of this new DTPw-HBV/Hib vaccine comprising antigens from a new source and a reduced PRP content for inclusion into routine childhood vaccination programs.

Trial registration: http://www.clinicaltrials.gov NCT00332566.

\section{Background}

Combined diphtheria-tetanus-whole cell pertussis (DTPw) vaccines remain the cornerstone of childhood vaccination programs in Latin America and many other parts of the world [1]. The addition of new antigens to existing vaccines with established high coverage rates is an efficient method of rapidly achieving high coverage and protection against other important pathogens with

\footnotetext{
* Correspondence: jeanne.jacquet@gskbio.com

${ }^{5}$ GlaxoSmithKline Biologicals, Buenos Aires, Argentina and Wavre, Belgium Full list of author information is available at the end of the article
}

minimum impact on vaccination logistics and cost [2-4]. Hepatitis B (HBV) and Haemophilus influenzae type b (Hib) infections remain endemic in many parts of the world, causing disease that can readily be prevented by vaccination $[5,6]$. Although universal vaccination of infants against HBV and Hib has been recommended by the World Health Organization (WHO) since 1992 and 1996, respectively [7-9], uptake of both vaccines is incomplete. Lack of appropriate combination vaccines and difficulties with vaccine supply have been identified as key factors contributing to this slow uptake [10].

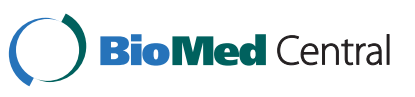


Tritanrix ${ }^{\text {tim }}$-HBV (GlaxoSmithKline [GSK] Biologicals, Rixensart, Belgium), a combined DTPw and hepatitis B vaccine, has been available since the mid-1990s [11]. This vaccine can be mixed with a conjugated Hib vaccine (Hiberix ${ }^{\mathrm{m}}$; GSK Biologicals) and administered as a single injection (Tritanrix $\left.{ }^{\text {ric }}-\mathrm{HBV} / \mathrm{Hib}\right)[11,12]$. In order to address the increasing international demand for DTPw-based combination vaccines, GSK Biologicals has recently introduced a new source of DTPw antigens and has developed a new DTPw-HBV/Hib combination vaccine containing a reduced amount of Hib capsular polyribosylribitol phosphate (PRP) $(2.5 \mu \mathrm{g}$ per $0.5 \mathrm{~mL}$ dose instead of the $10 \mu \mathrm{g}$ PRP contained in Tritanrix ${ }^{\text {Tm}}-\mathrm{HBV} /$ Hib). DTPw-based combination vaccines with reduced PRP antigen content have been shown to be noninferior to those with higher PRP antigen content in terms of immune response to all component antigens after primary and booster vaccination [13-18].

The ability to co-administer DTPw-based combination vaccines with other routine vaccines would be convenient for both medical staff and vaccine recipients. Studies have shown the potential for co-administration of combined DTPw-based combination vaccines with other pediatric vaccines, including rotavirus vaccine and oral poliovirus vaccine (OPV) [19]. This study was undertaken to assess the immunogenicity and reactogenicity of GSK Biological's new DTPw-HBV/Hib vaccine compared with Tritanrix ${ }^{\text {rm }}-\mathrm{HBV} / \mathrm{Hib}$ when co-administered with OPV in healthy Latin American infants at 2, 4 and 6 months. Antibody persistence and immune response to a booster dose at 18-24 months of age was also assessed.

\section{Methods}

\section{Study design and subjects}

This was a randomized, partially-blind, multicenter study in three countries in Latin America (Argentina, Chile and Nicaragua) between August 2004 and September 2005 . The study was approved by the appropriate local ethics committees and conducted in accordance with the Declaration of Helsinki and Good Clinical Practice guidelines. Healthy male and female infants born after a normal gestation period (between 36-42 weeks) were enrolled for first vaccination at 6-10 weeks of age. In Argentina, mothers of prospective participants were screened prenatally for the presence of hepatitis B virus surface antigen ( $\mathrm{HBsAg}$ ). Infants born to antiHBsAg seropositive mothers were ineligible for study participation, but were offered HBV vaccination at birth. Other exclusion criteria included: previous diphtheria, tetanus, pertussis, hepatitis $\mathrm{B}, \mathrm{Hib}$ or polio vaccination or disease; Bacille Calmette-Guérin vaccine given later than the first 2 weeks of life; major congenital defects or serious chronic illness; a history of allergic disease or reactions likely to be exacerbated by any component of the vaccine; a history of neurological disease, including previous seizures; any immune deficiency and prior or planned use of any blood products, immunoglobulins or immunosuppressive therapy; and acute illness at the time of enrolment. Written informed consent was obtained from the parent or guardian of each infant prior to study entry.

Subjects were randomized in a 1:1:1:1 ratio to receive either one of three lots of the new DTPw-HBV/Hib vaccine or the control vaccine (Tritanrix $\left.{ }^{\text {im }}-\mathrm{HBV} / \mathrm{Hib}\right)$ coadministered with OPV at 2, 4 and 6 months of age. The three different production lots of the new DTPw$\mathrm{HBV} / \mathrm{Hib}$ vaccine were administered in a double-blind manner. Blinding was single-blind with regard to the control vaccine group since the appearance of the two vaccines was not exactly the same. Subjects in Nicaragua and Argentina who had completed the 3-dose primary vaccination course were invited to receive a booster dose of the same DTPw-HBV/Hib combination vaccine at 18-24 months of age. The booster study took place between June and October 2006.

\section{Objectives}

The two co-primary objectives of this study were to demonstrate both lot-to-lot-consistency of the new DTPw-HBV/Hib vaccine and non-inferiority of the new DTPw-HBV/Hib vaccine to Tritanrix ${ }^{\text {Tw }}-\mathrm{HBV} / \mathrm{Hib}$ in terms of antibody response one month after the third primary vaccine dose. For all vaccine antigens, antibody persistence was assessed prior to booster administration and antibody responses were assessed one month after administration of the booster dose.

\section{Vaccines}

All vaccines were manufactured by GSK Biologicals. The diphtheria and tetanus antigens were sourced form GSK Biologicals Korlatolt Felelossegu Tarsasag (Hungary) and Pw was obtained from Commonwealth Serum Laboratory Ltd. (Australia) for the new DTPw-HBV/Hib vaccine. Both vaccines contained $\geq 30$ international units (IU) diphtheria toxoid, $\geq 60$ IU tetanus toxoid, $\geq 4$ IU killed Bordetella pertussis, and $10 \mu \mathrm{g}$ HBsAg. The new DTPw-HBV/Hib vaccine contained $2.5 \mu \mathrm{g}$ of Hib capsular PRP polysaccharide conjugated to $5-10 \mu \mathrm{g}$ tetanus toxoid. Tritanrix $x^{\mathrm{Tw}}-\mathrm{HBV} / \mathrm{Hib}$ contained $10 \mu \mathrm{g}$ of $\mathrm{Hib}$ capsular PRP polysaccharide conjugated to 20-40 $\mu \mathrm{g}$ tetanus toxoid. Both vaccines were administered as a 0.5 $\mathrm{mL}$ intramuscular injection into the anterolateral region of the left thigh. All subjects received OPV concomitantly with each primary dose.

\section{Serology}

Blood samples were collected prior to administration of the first vaccine dose and one month after completion 
of the 3-dose primary course. Blood samples were also taken before and one month after administration of the booster dose. Samples were stored at $-20^{\circ} \mathrm{C}$ until testing at GSK Biologicals' central laboratory in Rixensart, Belgium. Concentrations of antibodies against all vaccine antigens were determined by enzyme-linked immunosorbent assay (ELISA). Assay cut-offs were $0.1 \mathrm{IU} / \mathrm{mL}$ for diphtheria and tetanus, $15 \mathrm{IU} / \mathrm{mL}$ for Bordetella pertussis toxin (BPT), $10 \mathrm{mIU} / \mathrm{mL}$ for HBsAg and $0.15 \mu \mathrm{g} /$ $\mathrm{mL}$ for PRP. Pre-booster samples that were negative by ELISA were retested with the more sensitive in vitro neutralization assay on Vero cells with a cut-off of 0.016 $\mathrm{mIU} / \mathrm{ml}$.

With the exception of anti-BPT, antibody concentrations equal to or greater than the assay cut-off were considered to be protective. As no correlate of protection is established for $B$. pertussis, a vaccine response to this vaccine component was defined. For primary vaccination, a pertussis vaccine response was defined as the appearance of anti-BPT antibodies in initially seronegative subjects, or the presence of a post-vaccination antibody concentration greater than or equal to the initial pre-vaccination concentration. A booster response against the pertussis component was defined as the appearance of anti-BPT antibodies in pre-booster seronegative subjects, or at least a 2 -fold increase in antiBPT antibody concentration in subjects seropositive prior to boosting.

\section{Reactogenicity and safety}

Parents/guardians used diary cards to record the occurrence of solicited local (pain, redness and swelling at the site of injection) and general (drowsiness, fever [defined as rectal temperature $\geq 38^{\circ} \mathrm{C}$ ], irritability and loss of appetite) symptoms during a 4-day follow-up period after each vaccination. Intensity of symptoms was graded on a scale of $0-3$. Grade 3 symptoms were defined as follows: for local pain as crying when limb is moved or a spontaneously painful limb; for local redness and swelling as diameter $>20 \mathrm{~mm}$; for fever as rectal temperature $>40.0^{\circ} \mathrm{C}$; and for all other symptoms as preventing normal daily activities. All other (unsolicited) adverse events were recorded for a period of 30 days after each vaccination. Serious adverse events (SAEs) were recorded during the entire study period. All solicited local symptoms were considered causally related to vaccination. Causality of solicited general symptoms, unsolicited symptoms and SAEs was assessed by the investigator.

\section{Statistical analysis}

The target sample size was 500 evaluable subjects for immunogenicity (125 subjects per vaccine group). Considering that approximately $15 \%$ of enrolled subjects might withdraw or be unevaluable for immunogenicity; the target enrolment size was 600 subjects (150 subjects per vaccine group).

Analysis of immunogenicity was performed on the according-to-protocol (ATP) cohort and the analysis of safety was performed on the total vaccinated cohort.

Seroprotection rates against diphtheria, tetanus, HBsAg and PRP and vaccine response rates to BPT were calculated with $95 \%$ CIs. Standardized asymptotic 95\% CIs for the differences in seroprotection/vaccine response rates between the pooled DTPw-HBV/Hib groups and the Tritanrix ${ }^{\text {ti }}-\mathrm{HBV} / \mathrm{Hib}$ group one month after the third primary vaccine dose were computed. The response to the new DTPw-HBV/Hib vaccine was considered non-inferior to that of the control vaccine if the upper limit of the $95 \% \mathrm{CI}$ for the absolute difference between groups was lower than $10 \%$ for D, T, PRP and HBs. GMCs with $95 \% \mathrm{CI}$ were calculated by taking the log-transformation of individual concentrations and calculating the anti-log of the mean of these transformed values. Antibody concentrations below the assay cut-off were given an arbitrary value of half the cut-off value for the purpose of GMC calculation. For, D, T, PRP and HBs antigens, 95\% CIs for the GMC ratio (control over pooled DTPw-HBV/Hib groups) one month after primary vaccination were computed using an ANOVA model on the logarithm in base $10\left(\log _{10}\right)$ transformation of the concentrations using the vaccine group as covariate, while for pertussis, the $95 \% \mathrm{CI}$ for the GMC ratio was computed using an ANCOVA model with the vaccine group and the $\log _{10}$ concentrations prior to vaccination as covariates.

The incidence of solicited local and general symptoms (any or Grade 3 intensity) was calculated with exact 95\% CI. Differences between groups were compared using two-sided Fisher exact tests. P-values $<0.05$ were considered as possibly indicative of a statistically significant difference between groups.

The statistical analyses were performed using the Statistical Analysis Systems (SAS) version 8.2 on Windows XP Professional and StatXact-5 procedure on SAS.

\section{Results}

A total of 585 subjects were enrolled and received primary vaccination (439 in the DTPw-HBV/Hib group and 146 in the Tritanrix ${ }^{\text {тw }}$-HBV/Hib group). Of these, 147 subjects received booster vaccination at 18-24 months of age (113 and 34 subjects in the two groups, respectively). The relatively low proportion of subjects evaluated for booster vaccination is due to only two countries out of three (Argentina and Nicaragua) participating in the booster study. The mean $( \pm S D)$ age of the total cohort at the time of first vaccination was 7.8 $( \pm 1.12)$ weeks, $52.0 \%$ of subjects were male and $56.6 \%$ 
were American Hispanic. The mean $( \pm \mathrm{SD})$ age at the time of the booster dose was $18.9( \pm 0.7)$ months and $59.9 \%$ of subjects were male. The population was predominantly American Hispanic (78.2\%); the other subjects were White/Caucasian. No clinically significant differences in demography were seen between groups. Subject disposition is summarized in Figure 1.

\section{Immunogenicity}

Seroprotection/vaccine response rates and antibody GMCs for all vaccine antigens are shown in Table 1 . The new DTPw-HBV/Hib vaccine was found to be non-inferior to Tritanrix ${ }^{\text {tri }}-\mathrm{HBV} / \mathrm{Hib}$ in terms of seroprotection against diphtheria, tetanus, HBs and PRP antigens following primary vaccination. One month after completion of the 3-dose primary course, $99.0 \%$ of subjects in the DTPw-HBV/Hib group and 100\% of those in the Tritanrix $^{\text {rm }}-\mathrm{HBV} / \mathrm{Hib}$ group had anti-PRP antibody concentrations $\geq 0.15 \mu \mathrm{g} / \mathrm{mL}$, with anti-PRP antibody concentrations $\geq 1.0 \mu \mathrm{g} / \mathrm{mL}$ in $97.3 \%$ and $100 \%$ of subjects in the two groups, respectively. At least $97.7 \%$ of subjects in the DTPw-HBV/Hib group and $93.9 \%$ of those in the Tritanrix $x^{\text {rm }}-\mathrm{HBV} / \mathrm{Hib}$ group had seroprotective levels of antibodies against diphtheria, tetanus and hepatitis B and a vaccine response to the pertussis component at this time. Post-primary vaccination GMCs for anti-diphtheria and anti-HBs antibodies were significantly higher (nonoverlapping $\mathrm{CI}$ ) in the $\mathrm{DTPw}-\mathrm{HBV} / \mathrm{Hib}$ group than in the Tritanrix ${ }^{\text {rn }}$-HBV/Hib control group, while anti-PRP GMC was significantly higher in the Tritanrix ${ }^{\text {tm }}-\mathrm{HBV} / \mathrm{Hib}$ group than in the DTPw-HBV/Hib group (21.4 and 12.5 $\mu \mathrm{g} / \mathrm{mL}$, respectively; non-overlapping $\mathrm{CI}$ ).

Prior to booster administration at 18-24 months, antiPRP antibody concentrations remained $\geq 0.15 \mu \mathrm{g} / \mathrm{mL}$ in $95.5 \%$ of subjects in the DTPw-HBV/Hib and $100 \%$ of those in the Tritanrix ${ }^{\mathrm{m}}-\mathrm{HBV} / \mathrm{Hib}$ group. More than $81.7 \%$ and $75.8 \%$ of subjects in the two groups, respectively, still had seroprotective levels of antibodies to diphtheria (by ELISA), tetanus and hepatitis B at this time, with $32.7 \%$ and $36.4 \%$ of subjects remaining seropositive for anti-BPT antibodies (data not shown). Testing of seronegative samples by the Vero cell neutralisation assay showed a global seroprotection rate against diphtheria of $90.5 \%$ and $82.4 \%$ in the two groups, respectively. No differences in pre-booster antibody GMCs were seen between the two groups, with the exception of a significantly higher anti-PRP GMC in the Tritanrix ${ }^{\mathrm{Tm}}$ $\mathrm{HBV} / \mathrm{Hib}$ group (2.1 compared with $1.0 \mu \mathrm{g} / \mathrm{mL}$ in the DTPw-HBV/Hib group; non-overlapping CI).

A marked booster response to all vaccine antigens was observed in both groups. One month after booster administration, all subjects had anti-PRP antibody concentrations $\geq 0.15 \mu \mathrm{g} / \mathrm{mL}$, with anti-PRP antibody concentrations $\geq 1.0 \mu \mathrm{g} / \mathrm{mL}$ in all but one subject in the
DTPw-HBV/Hib vaccine group. At least $99.1 \%$ of subjects in the DTPw-HBV/Hib group and $97.1 \%$ of those in the Tritanrix ${ }^{\text {Tn}}-\mathrm{HBV} / \mathrm{Hib}$ group had seroprotective levels of antibodies against diphtheria, tetanus and hepatitis $\mathrm{B}$ and a booster response to the pertussis component following booster administration. Post-booster GMCs did not appear to differ between the two groups, with the exception of anti-PRP GMC which remained significantly higher in the Tritanrix ${ }^{\mathrm{mi}}-\mathrm{HBV} / \mathrm{Hib}$ group than in the DTPw-HBV/Hib group (66.6 and $33.4 \mu \mathrm{g} /$ $\mathrm{mL}$, respectively; non-overlapping $\mathrm{CI}$ ).

\section{Reactogenicity and safety}

The overall incidence of solicited local and general symptoms following primary and booster doses is shown in Table 2. Pain was the most frequent local solicited symptom in both groups. Grade 3 pain appeared to be more common in the DTPw-HBV/Hib group than in the Tritanrix ${ }^{\text {tw }}-\mathrm{HBV} / \mathrm{Hib}$ group after both primary and booster doses $(21.8 \%$ and $15.4 \%$ in the two groups, respectively, following primary vaccination; non-overlapping CI, and $43.4 \%$ and $23.5 \%$, respectively, after the booster dose). Irritability and fever were the most common general solicited symptoms. One subject in each group withdrew due to Grade 3 irritability following administration of the first primary dose. Irritability occurred more frequently after the booster dose in the DTPw-HBV/Hib group than in the Tritanrix ${ }^{\mathrm{xm}}-\mathrm{HBV} / \mathrm{Hib}$ group $(71.7 \%$ versus $47.1 \%$, respectively). The incidence of fever (rectal temperature $\geq 38.0^{\circ} \mathrm{C}$ ) was higher in the DTPw-HBV/Hib group than in the Tritanrix ${ }^{\mathrm{x}}-\mathrm{HBV} / \mathrm{Hib}$ group following both primary and booster vaccination (56.9\% versus $46.7 \%$; non-overlapping $\mathrm{CI}$ and $70.8 \%$ versus $58.8 \%$, respectively). However, the incidence of rectal temperature $\geq 40.0^{\circ} \mathrm{C}$ was low and similar in both groups after all doses. Very few subjects required medical advice for solicited symptoms following either primary or booster doses (Table 2).

The incidence of unsolicited symptoms considered related to vaccination did not differ between groups (17.7\% of the doses administered in the DTPw-HBV/ Hib group and $17.1 \%$ in the Tritanrix ${ }^{\text {Tw }}-\mathrm{HBV} / \mathrm{Hib}$ group after primary vaccination and none were reported in either of the groups after the booster dose). The most common unsolicited symptom considered related to vaccination after primary vaccination was injection site reactions in both groups. Injection site induration was reported following $15.9 \%$ and $15.6 \%$ of the vaccine doses in the DTPw-HBV/Hib and in the Tritanrix ${ }^{\mathrm{Tm}}-\mathrm{HBV} / \mathrm{Hib}$ groups respectively. Two SAEs considered related to vaccination were reported during the primary course. Both of these events occurred in the DTPw-HBV/Hib group and required hospitalization, but resolved without sequelae. One subject who presented persistent crying 


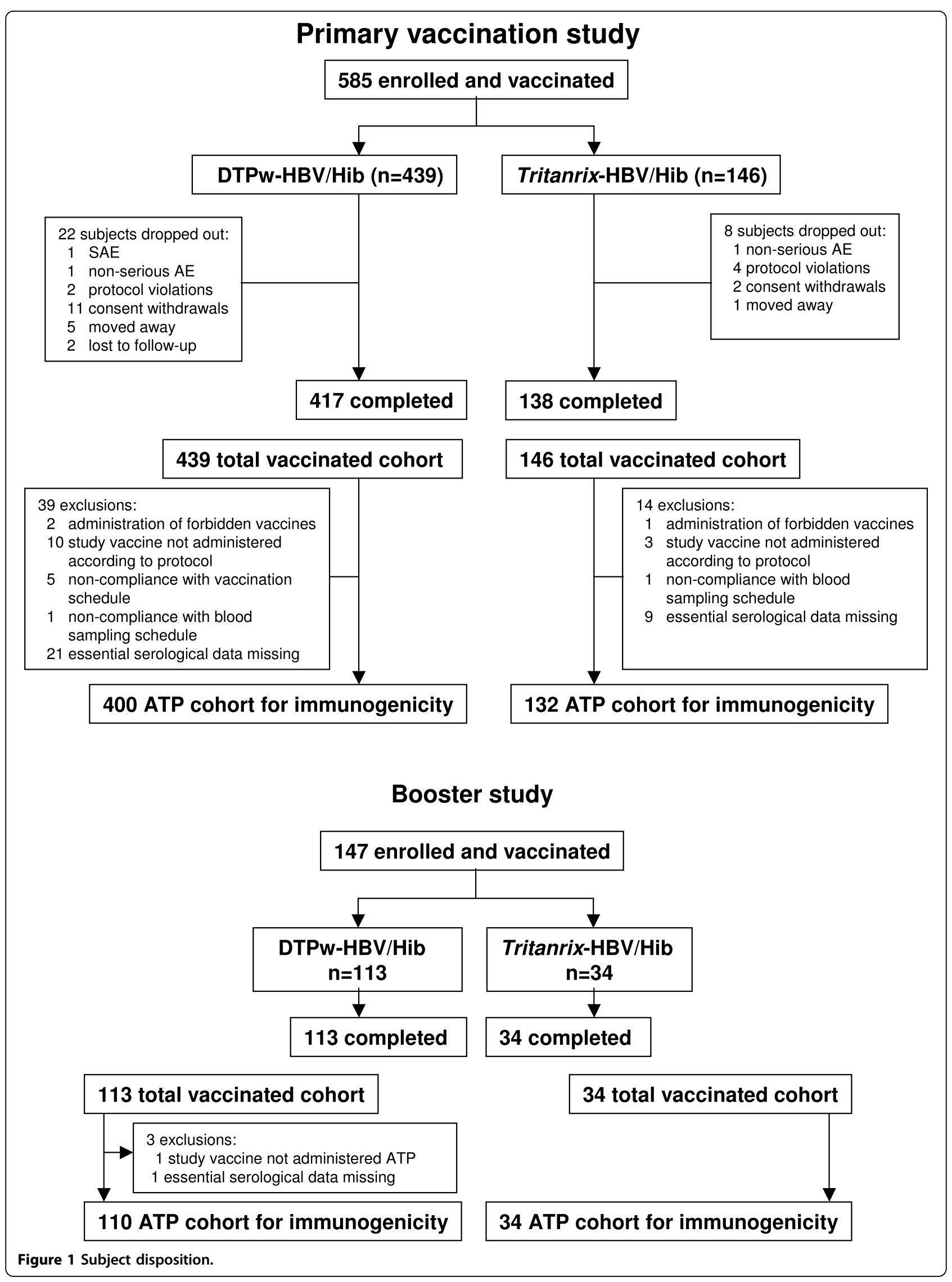


Table 1 Seroprotection (SP), vaccine response (VR) rates and GMCs one month post-primary and pre- and one month post-booster vaccination (ATP immunogenicity cohort)

\begin{tabular}{|c|c|c|c|c|c|c|c|c|c|}
\hline \multirow[b]{2}{*}{ Group } & \multirow[b]{2}{*}{$\mathbf{N}$} & \multicolumn{2}{|c|}{ Post-Primary } & \multicolumn{3}{|c|}{ Pre-Booster } & \multicolumn{3}{|c|}{ Post-Booster } \\
\hline & & $\begin{array}{l}\% \text { SP/VR } \\
(95 \% \mathrm{Cl}) \\
\end{array}$ & $\begin{array}{c}\text { GMC } \\
(95 \% \mathrm{Cl})\end{array}$ & $\mathbf{N}$ & $\begin{array}{c}\% \mathrm{SP} \\
(95 \% \mathrm{Cl}) \\
\end{array}$ & $\begin{array}{c}\mathrm{GMC} \\
(95 \% \mathrm{Cl})\end{array}$ & $\mathrm{N}$ & $\begin{array}{l}\% \mathrm{SP} / \mathrm{BR} \\
(95 \% \mathrm{Cl}) \\
\end{array}$ & $\begin{array}{c}\text { GMC } \\
(95 \% \mathrm{Cl})\end{array}$ \\
\hline \multicolumn{10}{|c|}{$\begin{array}{l}\text { Anti-diphtheria }(\geq 0.1 \\
\text { IU } / \mathrm{mL})\end{array}$} \\
\hline DTPw-HBV/Hib & 398 & $\begin{array}{c}97.7(95.8 \\
99.0)\end{array}$ & $\begin{array}{l}2.093 \S(1.851 \\
2.366)\end{array}$ & 109 & $\begin{array}{l}81.7(73.1 \\
88.4)\end{array}$ & $\begin{array}{l}0.263(0.218 \\
0.316)\end{array}$ & 110 & $\begin{array}{l}100(96.7 \\
100)\end{array}$ & $6.755(5.726,7.970)$ \\
\hline Tritanrix ${ }^{\mathrm{TM}}-\mathrm{HBV} / \mathrm{Hib}$ & 132 & $\begin{array}{c}93.9(88.4 \\
97.3)\end{array}$ & $\begin{array}{c}1.350 \S(1.077 \\
1.691)\end{array}$ & 33 & $\begin{array}{l}75.8(57.7 \\
88.9)\end{array}$ & $\begin{array}{l}0.214(0.153 \\
0.300)\end{array}$ & 34 & $\begin{array}{l}100(89.7 \\
100)\end{array}$ & $4.974(3.197,7.738)$ \\
\hline \multicolumn{10}{|c|}{$\begin{array}{l}\text { Anti-tetanus ( } \geq 0.1 \mathrm{IU} / \\
\mathrm{mL} \text { ) }\end{array}$} \\
\hline DTPw-HBV/Hib & 399 & $\begin{array}{l}99.7(98.6 \\
100)\end{array}$ & $6.679(6.084,7.333)$ & 110 & $\begin{array}{l}98.2(93.6 \\
99.8)\end{array}$ & $\begin{array}{l}0.652(0.555 \\
0.767)\end{array}$ & 110 & $\begin{array}{l}100(96.7 \\
100)\end{array}$ & $\begin{array}{l}18.555(16.406 \\
20.984)\end{array}$ \\
\hline Tritanrix ${ }^{\mathrm{TM}}-\mathrm{HBV} / \mathrm{Hib}$ & 131 & $\begin{array}{c}100(97.2 \\
100)\end{array}$ & $5.884(4.964,6.974)$ & 34 & $\begin{array}{l}100(89.7 \\
100)\end{array}$ & $\begin{array}{l}0.748(0.564 \\
0.991)\end{array}$ & 34 & $\begin{array}{l}100(89.7 \\
100)\end{array}$ & $\begin{array}{l}15.430(12.205 \\
19.507)\end{array}$ \\
\hline \multicolumn{10}{|c|}{ Anti-HBs ( $\geq 10 \mathrm{mlU} / \mathrm{mL}$ ) } \\
\hline DTPw-HBV/Hib & 400 & $\begin{array}{l}99.8(98.6 \\
100)\end{array}$ & $\begin{array}{c}2417.5 \S(2127.3 \\
2747.3)\end{array}$ & 110 & $\begin{array}{l}94.5(88.5 \\
98.0)\end{array}$ & $\begin{array}{c}126.9(98.1 \\
164.2)\end{array}$ & 110 & $\begin{array}{l}99.1(95.0 \\
100)\end{array}$ & $\begin{array}{c}19247.5(14422.5 \\
25686.6)\end{array}$ \\
\hline Tritanrix ${ }^{T M}-\mathrm{HBV} / \mathrm{Hib}$ & 132 & $\begin{array}{c}97.7(93.5 \\
99.5)\end{array}$ & $\begin{array}{l}\text { 1319.3§ (1035.8, } \\
1680.3)\end{array}$ & 34 & $\begin{array}{c}94.1(80.3, \\
99.3)\end{array}$ & $97.3(65.5,144.3)$ & 34 & $\begin{array}{l}97.1(84.7 \\
99.9)\end{array}$ & $\begin{array}{l}14366.8(7612.5 \\
27114.2)\end{array}$ \\
\hline \multicolumn{10}{|c|}{ Anti-PRP $(\geq 0.15 \mu \mathrm{g} / \mathrm{mL})$} \\
\hline DTPw-HBV/Hib & 400 & $\begin{array}{l}99.0(97.5 \\
99.7)\end{array}$ & $\begin{array}{l}12.530 \S(11.180 \\
14.043)\end{array}$ & 110 & $\begin{array}{l}95.5(89.7 \\
98.5)\end{array}$ & $\begin{array}{c}1.006 \S(0.768 \\
1.319)\end{array}$ & 110 & $\begin{array}{l}100(96.7 \\
100)\end{array}$ & $\begin{array}{l}34.364 \S(27.563 \\
42.843)\end{array}$ \\
\hline Tritanrix $^{\mathrm{TM}}$-HBV/Hib & 132 & $\begin{array}{c}100(97.2 \\
100)\end{array}$ & $\begin{array}{c}21.393 \S(17.971 \\
25.467)\end{array}$ & 34 & $\begin{array}{l}100(89.7 \\
100)\end{array}$ & $\begin{array}{l}2.059 \S(1.357 \\
3.123)\end{array}$ & 34 & $\begin{array}{l}100(89.7 \\
100)\end{array}$ & $\begin{array}{l}66.616 \S(43.734 \\
101.468)\end{array}$ \\
\hline \multicolumn{10}{|c|}{ Anti-PRP $(\geq 1.0 \mu \mathrm{g} / \mathrm{mL})$} \\
\hline DTPw-HBV/Hib & 400 & $\begin{array}{l}97.3(95.1 \\
98.6)\end{array}$ & - & 110 & $\begin{array}{l}46.4(36.8 \\
56.1)\end{array}$ & - & 110 & $\begin{array}{l}99.1(95.0 \\
100)\end{array}$ & - \\
\hline Tritanrix ${ }^{T M}-\mathrm{HBV} / \mathrm{Hib}$ & 132 & $\begin{array}{c}100(97.2 \\
100)\end{array}$ & - & 34 & $\begin{array}{c}79.4(62.1 \\
91.3)\end{array}$ & - & 34 & $\begin{array}{c}100(89.7 \\
100)\end{array}$ & - \\
\hline \multicolumn{10}{|c|}{ Anti-BPT (VR or BR) } \\
\hline DTPw-HBV/Hib & $394^{*}$ & $\begin{array}{c}97.9 \text { (96.0 } \\
99.1)\end{array}$ & $82.6(76.7,89.1)$ & 110 & & $10.9(9.8,12.1)$ & 109 & $\begin{array}{c}99.1(95.0 \\
100)\end{array}$ & $105.1(93.6,118.0)$ \\
\hline Tritanrix ${ }^{\mathrm{T}}-\mathrm{HBV} / \mathrm{Hib}$ & 131 & $\begin{array}{c}95.4(90.3 \\
98.3)\end{array}$ & $90.5(77.7,105.5)$ & 33 & & $11.1(9.1,13.7)$ & $34 \#$ & $\begin{array}{c}100(89.5 \\
100)\end{array}$ & $128.4(99.2,166.3)$ \\
\hline
\end{tabular}

$\mathrm{N}=$ number of subjects with available results; ${ }^{*} 390$ subjects for vaccine response; \#33 subjects for booster response.

Vaccine (VR) response to the pertussis component defined as the appearance of antibody concentration $\geq 15$ EL.U/mL in subjects seronegative at pre-vaccination or maintenance of pre-vaccination antibody concentrations one month after the third dose in initially seropositive subjects prior to primary vaccination.

Booster (BR) response to the pertussis component defined as the appearance of antibody concentration $\geq 15$ EL.U/mL in subjects seronegative at pre-booster or post-booster antibody concentration two-fold higher than pre-booster antibody concentrations in initially seropositive subjects prior to the booster vaccination. $\% \mathrm{SP}=$ percentage of subjects who achieve seropositivity as is described for each antigen; $\mathrm{GMC}=$ geometric mean antibody concentration; $95 \% \mathrm{Cl}=95 \%$ confidence interval; § non-overlapping $\mathrm{Cl}$.

on the day of administration of the first primary dose remained to complete the 3 -dose primary vaccination course. The other subject experienced erythema and induration at the vaccine injection site six days after vaccination. The subject was diagnosed as having left thigh abscess and was treated. Following discharge the subject recovered, but was subsequently withdrawn from the study. No SAEs considered related to vaccination were reported after booster administration.

\section{Discussion}

Clinical experience shows DTPw-HBV/Hib combination vaccines to be an efficient and reliable method of implementing WHO recommendations for controlling diphtheria, tetanus, pertussis, hepatitis B and Hib infections on a worldwide basis [11]. For the new vaccine evaluated in this study, new antigen sources and reduced antigen content were used to ensure continued vaccine supply for global mass vaccination campaigns. This DTPw-HBV/Hib combination vaccine is based on the same formulation as the licensed Tritanrix ${ }^{\text {Tm }}-\mathrm{HBV} /$ Hib vaccine $[12,20]$, but containing diphtheria, tetanus and pertussis antigens from an alternative source and a lower amount of the PRP capsular polysaccharide component of $\mathrm{Hib}(2.5$ instead of $10 \mu \mathrm{g} / \mathrm{mL}$ per $0.5 \mathrm{ml}$ dose). The study was designed and powered for immunogenicity comparison in primary vaccination; booster evaluation was purely descriptive and conducted in a 
Table 2 Incidence (\% [95\% Cl]) of solicited local and general symptoms during the 4 days following primary (overall/ dose) and booster vaccination (Total vaccinated cohort)

\begin{tabular}{|c|c|c|c|c|}
\hline \multirow[b]{2}{*}{ Solicited symptom } & \multicolumn{2}{|c|}{ Primary doses } & \multicolumn{2}{|c|}{ Booster dose } \\
\hline & $\begin{array}{l}\text { DTPw-HBV/Hib } \\
(\mathrm{N}=1274)\end{array}$ & $\begin{array}{c}\text { Tritanrix }{ }^{\mathrm{TM}}-\mathrm{HBV} / \mathrm{Hib} \\
(\mathrm{N}=422)\end{array}$ & $\begin{array}{c}\text { DTPw-HBV/Hib } \\
(\mathrm{N}=113)\end{array}$ & $\begin{array}{c}\text { Tritanrix }^{\mathrm{TM}}-\mathrm{HBV} / \mathrm{Hib} \\
(\mathrm{N}=34)\end{array}$ \\
\hline \multicolumn{5}{|l|}{ Pain } \\
\hline Any & $73.4(70.9,75.8)$ & $69.4(64.8,73.8)$ & $90.3(83.2,95.0)$ & $79.4(62.1,91.3)$ \\
\hline Grade 3 & $21.8(19.6,24.2) \S$ & $15.4(12.1,19.2) \S$ & $43.4(34.1,53.0)$ & $23.5(10.7,41.2)$ \\
\hline MA & $0.5(0.2,1.1)$ & $0.5(0.1,1.7)$ & $0(0.0,3.2)$ & $0(0.0,10.3)$ \\
\hline \multicolumn{5}{|l|}{ Redness } \\
\hline Any & $53.1(50.4,55.9) \S$ & $44.1(39.3,49.0) \S$ & $48.7(39.2,58.3)$ & $44.1(27.2,62.1)$ \\
\hline$>20 \mathrm{~mm}$ & $17.3(15.2,19.5)$ & $12.8(9.8,16.4)$ & $14.2(8.3,22.0)$ & $11.8(3.3,27.5)$ \\
\hline MA & $0.6(0.3,1.2)$ & $0(0.0,0.9)$ & $0(0.0,3.2)$ & $0(0.0,10.3)$ \\
\hline \multicolumn{5}{|l|}{ Swelling } \\
\hline Any & $51.1(48.3,53.9)$ & $46.4(41.6,51.3)$ & $64.6(55.0,73.4)$ & $38.2(22.2,56.4)$ \\
\hline$>20 \mathrm{~mm}$ & $21.7(19.4,24.0)$ & $23.2(19.3,27.6)$ & $28.3(20.2,37.6)$ & $17.6(6.8,34.5)$ \\
\hline MA & $0.7(0.3,1.3)$ & $0.2(0.0,1.3)$ & $0.9(0.0,4.8)$ & $0(0.0,10.3)$ \\
\hline \multicolumn{5}{|l|}{ Drowsiness } \\
\hline Any & $44.3(41.6,47.1)$ & $44.1(39.3,49.0)$ & $39.8(30.7,49.5)$ & $17.6(6.8,34.5)$ \\
\hline Grade 3 & $1.5(0.9,2.3)$ & $0.9(0.3,2.4)$ & $2.7(0.6,7.6)$ & $0(0.0,10.3)$ \\
\hline MA & $0.4(0.1,0.9)$ & $0.2(0.0,1.3)$ & $0(0.0,3.2)$ & $0(0.0,10.3)$ \\
\hline \multicolumn{5}{|l|}{ Rectal temperature } \\
\hline Any & $56.9(54.1,59.6) \S$ & $46.7(41.8,51.6) \S$ & $70.8(61.5,79.0)$ & $58.8(40.7,75.4)$ \\
\hline$>38.0^{\circ} \mathrm{C}$ & $56.9(54.1,59.6) \S$ & $46.7(41.8,51.6) \S$ & $38.1(29.1,47.7)$ & $14.7(5.0,31.1)$ \\
\hline$>38.5^{\circ} \mathrm{C}$ & $19.6(17.5,21.9)$ & $17.5(14.0,21.5)$ & $21.2(14.1,29.9)$ & $5.9(0.7,19.7)$ \\
\hline$>39.0^{\circ} \mathrm{C}$ & $6.9(5.6,8.4)$ & $5.0(3.1,7.5)$ & $1.8(0.2,6.2)$ & $2.9(0.1,15.3)$ \\
\hline$>39.5^{\circ} \mathrm{C}$ & $2.8(2.0,3.9)$ & $3.1(1.7,5.2)$ & $0.9(0.0,4.8)$ & $0.0(0.0,10.3)$ \\
\hline$>40.0^{\circ} \mathrm{C}$ & $0.5(0.2,1.0)$ & $0.7(0.1,2.1)$ & $0.0(0.0,3.2)$ & $0.0(0.0,10.3)$ \\
\hline MA & $1.2(0.7,1.9)$ & $0.5(0.1,1.7)$ & $0.0(0.0,3.2)$ & $0.0(0.0,10.3)$ \\
\hline \multicolumn{5}{|l|}{ Irritability } \\
\hline Any & $67.0(64.4,69.6)$ & $65.2(60.4,69.7)$ & $71.7(62.4,79.8)$ & $47.1(29.8,64.9)$ \\
\hline Grade 3 & $5.0(3.9,6.4)$ & $6.6(4.5,9.4)$ & $9.7(5.0,16.8)$ & $0(0.0,10.3)$ \\
\hline MA & $0.7(0.3,1.3)$ & $0.7(0.1,2.1)$ & $0(0.0,3.2)$ & $0(0.0,10.3)$ \\
\hline \multicolumn{5}{|l|}{ Loss of appetite } \\
\hline Any & $29.9(27.4,32.5)$ & $26.1(21.9,30.5)$ & $42.5(33.2,52.1)$ & $29.4(15.1,47.5)$ \\
\hline Grade 3 & $0.8(0.4,1.4)$ & $0.5(0.1,1.7)$ & $4.4(1.5,10.0)$ & $0(0.0,10.3)$ \\
\hline MA & $0.3(0.1,0.8)$ & $0.2(0.0,1.3)$ & $0(0.0,3.2)$ & $0(0.0,10.3)$ \\
\hline
\end{tabular}

$\mathrm{N}=$ number of doses; $\mathrm{MA}=$ medical advice sought for the symptom; $\S$ non-overlapping $\mathrm{Cl}$.

limited proportion of initially primed subjects. Co-administered with OPV at 2, 4 and 6 months of age, the new $\mathrm{DTPw}-\mathrm{HBV} / \mathrm{Hib}$ vaccine was found to be non-inferior to Tritanrix ${ }^{\mathrm{Tm}}-\mathrm{HBV} / \mathrm{Hib}$ in terms of seroprotection to the $\mathrm{D}, \mathrm{T}, \mathrm{HBs}$ and PRP vaccine antigens one month after completion of the 3-dose primary course. Immune response to all vaccine antigens was within the range previously reported for this or other similar DTPwbased vaccines [11-13,15-17,20].

Lot-to-lot consistency for the new DTPw-HBV/Hib vaccine was demonstrated, i.e., for anti-diphtheria, antitetanus, anti-HBs and anti-PRP, the standardized asymptotic $90 \%$ confidence intervals (CI) for the absolute difference between each pair of lots in the percentage of subjects seroprotected was within $[-10 \% ; 10 \%]$ and for
anti-BPT, the $90 \%$ confidence interval for the ratio of geometric mean antibody concentrations (GMCs) between each pair of lots was within $[0.5,2]$ (data not shown). Based on these findings, data for the three vaccine lots used in this study were pooled for comparison against the control vaccine.

Antibody GMCs induced by the new DTPw-HBV/Hib vaccine following primary vaccination were observed similar to those induced by Tritanrix ${ }^{\mathrm{Tm}}-\mathrm{HBV} / \mathrm{Hib}$, with the exception of anti-PRP GMC. However, almost all subjects achieved anti-PRP concentrations $\geq 1.0 \mu \mathrm{g} / \mathrm{mL}$ ( $\geq 97.3 \%)$ and post-primary anti-PRP GMCs were high (> $12.5 \mu \mathrm{g} / \mathrm{mL}$ ) in both groups, suggesting that intergroup differences are unlikely to be of clinical relevance. A large body of evidence shows reduction of the PRP 
content of Hib conjugate-based vaccines to have no negative impact on either immune response or induction of immune memory to Hib [21-26]. Effective induction of immune memory was demonstrated with the reduced-content Hib component used in this DTPw$\mathrm{HBV} / \mathrm{Hib}$ vaccine $[14,18]$. In our study, a high degree of antibody persistence and a vigorous booster response was seen for all vaccine antigens including PRP in both groups, indicative of effective priming and induction of immune memory with both vaccines.

The new DTPw-HBV/Hib vaccine was found to have an acceptable reactogenicity profile. Some differences in reactogenicity were observed between the two vaccines. However, since very few subjects in either group sought medical advice for solicited symptoms it is likely that any differences had minimal clinical impact. Also, as no correction for multiplicity of endpoints was applied, statistically significant differences in reactogenicity should be interpreted with caution. Very few subjects in this study failed to receive all planned vaccine doses due to adverse events ( 2 in the DTPw-HBV/Hib group and 1 in the Tritanrix ${ }^{\text {mit }}-\mathrm{HBV} / \mathrm{Hib}$ group). Indeed, by eliminating the need for multiple injections, such combination vaccines are likely to promote compliance with infant immunization schedules [2-4]. In both groups, the incidence of solicited symptoms was higher after the booster dose than after the primary doses, as has previously been reported following booster vaccination with DTPw- and diphtheria-tetanus-acellular pertussis based vaccines $[14,15,17,27,28]$.

\section{Conclusions}

In conclusion, the development of new DTPw-based combination vaccines is essential for the success of current and future childhood mass vaccination programs in countries where resources are limited. Combining DTPw vaccines with HBV and Hib performs a key role in increasing vaccine coverage rates in line with WHO targets. Results of this study confirm the suitability of GSK Biologicals' new DTPw-HBV/Hib vaccine containing DTPw antigens from a new source and a reduced quantity of PRP as an alternative to currently licensed DTPw-based combination vaccines for use as a primary or booster dose in routine pediatric vaccination programs.

\footnotetext{
Abbreviations

ATP: according to protocol; BPT: Bordetella pertussis toxin; Cl: confidence interval; DTPw: Diphtheria-tetanus-whole-cell pertussis; ELISA: enzyme-linked immunosorbent assay; GMC: geometric mean antibody concentration; GSK: GlaxoSmithKline Biologicals; HBsAg: hepatitis B virus surface antigen; Hib: Haemophilus influenzae type B; HBV: hepatitis B virus; IU: international units; OPV: oral poliovirus vaccine; PRP: polyribosylribitol phosphate; SAE: serious adverse events; SD: standard deviation; WHO: World Health Organization.
}

\section{Acknowledgements}

The authors would like to thank Jennifer Coward and Julia Donnelly for editorial assistance in the preparation of this manuscript and the laboratory assistants who undertook the serological assays.

Tritanrix and Hiberix are trademarks of the GlaxoSmithKline group of companies.

\section{Author details}

${ }^{1}$ Universidad Nacional Autonoma de Leon, Leon, Nicaragua. ${ }^{2}$ Centro de Desarrollo de Proyectos Avanzados, Cordoba, Argentina. ${ }^{3}$ Hospital de Niños Ricardo Gutierrez, Buenos Aires, Argentina. ${ }^{4}$ Pontificia Universidad Católica de Chile, Santiago, Chile. ${ }^{5}$ GlaxoSmithKline Biologicals, Buenos Aires, Argentina and Wavre, Belgium.

\section{Authors' contributions}

AC participated in the design of the study and performed the statistica analysis. FE, MT, AG, KA, JC, ILF, J-MJ conceived of the study, and participated in its design and coordination and helped to draft the manuscript. All authors read and approved the final manuscript.

\section{Competing interests}

This study was funded by GlaxoSmithKline Biologicals. JC, AC, ILF, J-MJ are employees of GlaxoSmithKline Biologicals or were employed at the time of the study.

All authors participated in the design or implementation, analysis and interpretation of the study, the writing of the report and the decision to submit the manuscript for publication.

Received: 25 February 2010 Accepted: 15 October 2010 Published: 15 October 2010

\section{References}

1. World Health Organization: Pertussis vaccines-WHO Position Paper. Wkly Epidemiol Rec 2005, 80(4):31-9.

2. Dodd D: Benefits of combination vaccines: effective vaccination on a simplified schedule. Am J Manag Care 2003, 9(1 Suppl):S6-12.

3. Kalies H, Grote V, Verstraeten T, Hessel L, Schmitt HJ, von Kries R: The use of combination vaccines has improved timeliness of vaccination in children. Pediatr Infect Dis J 2006, 25(6):505-12.

4. Marshall GS, Happe LE, Lunacsek OE, Szymanski MD, Woods CR, Zahn M, Russell A: Use of combination vaccines is associated with improved coverage rates. Pediatr Infect Dis J 2007, 26(6):496-500.

5. Cowgill KD, Ndiritu M, Nyiro J, Slack MP, Chiphatsi S, Ismail A, Kamau T, Mwangi I, English M, Newton CR, Feikin DR, Scott JA: Effectiveness of Haemophilus influenzae type $\mathrm{b}$ conjugate vaccine introduction into routine childhood immunization in Kenya. JAMA 2006, 296(6):671-8.

6. Lee EH, Lewis RF, Makumbi I, Kekitiinwa A, Ediamu TD, Bazibu M, Braka F, Flannery B, Zuber PL, Feikin DR: Haemophilus influenzae type b conjugate vaccine is highly effective in the Ugandan routine immunization program: a case-control study. Trop Med Int Health 2008, 13(4):495-502

7. World Health Organization: Expanded programme on immunization: Global advisory group-Part I. Wkly Epidemiol Rec 1992, 67(3):11-5.

8. World Health Organization: Global programme for vaccines and immunization. The WHO position paper on Haemophilus influenzae type b conjugate vaccines. Wkly Epidemiol Rec 1998, 73(10):64-8.

9. World Health Organization: WHO position paper on Haemophilus influenzae type b conjugate vaccines. Wkly Epidemiol Rec 2006, 81(47):445-52.

10. Wenger $\mathrm{J}$ : Vaccines for the developing world: current status and future directions. Vaccine 2001, 19(13-14):1588-91.

11. Prymula R, Plisek S: Clinical experience with DTPw-HBV and DTPw-HBV/ Hib combination vaccines. Exp Opin Biol Ther 2008, 8(4):503-13.

12. Arístegui J, Usonis V, Coovadia H, Riedemann S, Win KM, Gatchalian S, Bock HL: Facilitating the WHO expanded program of immunization: the clinical profile of a combined diphtheria, tetanus, pertussis, hepatitis B and Haemophilus influenzae type b vaccine. Int J Infect Dis 2003, 7(2):143-51.

13. Gatchalian S, Reyes M, Bernal N, Lefevre I, David MP, Han HH, Bock HL, Wolter J, Schuerman L: A new DTPw-HBV vaccine is immunogenic and safe when administered according to the EPI (Expanded Programme for 
Immunization) schedule and following hepatitis B vaccination at birth. Hum Vaccin 2005, 1(5):198-203.

14. Hla KH, Thein SA, Aye A, Han HH, Bock HL, David MP, Schuerman L: Reactogenicity and immunogenicity profiles of a novel pentavalent diphtheria-tetanus-whole cell pertussis-hepatitis B and Haemophilus influenzae type $B$ vaccine: a randomized dose-ranging trial of the Hib tetanus-conjugate content. Pediatr Infect Dis J 2006, 25(8):706-12.

15. Tregnaghi M, López P, Rocha C, Rivera L, David MP, Rüttimann R, Schuerman L: A new DTPw-HB/Hib combination vaccine for primary and booster vaccination of infants in Latin America. Rev Panam Salud Publica 2006, 19(3):179-88

16. Ortega-Barrìa E, Kanra G, Leroux G, Bravo L, Safary A, Lefevre I, DTPW-HBV/ Hib 2.5 study group: The immunogenicity and reactogenicity of DTPwHBV/Hib 2.5 combination vaccine: Results from four phase III multicenter trials across three continents. Vaccine 2007, 25(50):8432-40.

17. Prymula R, David MP, Lefevre I, Kohl I, Stefkovicová M: The immunogenicity and reactogenicity of a new DTPw-HBV vaccine as a primary and booster vaccination course in healthy infants. Hum Vaccin 2007 3(4):121-6.

18. Gatchalian S, Reyes M, Bermal N, Chandrasekaran V, Han HH, Bock HL, Lefevre I: A new DTPw-HBV/Hib vaccine: Immune memory after primary vaccination and booster dosing in the second year of life. Human Vaccines 2008, 4(1):60-6.

19. Linhares AC, Ruiz-Palacios GM, Guerrero ML, Salinas B, Perez-Schael I, Clemens SC, Cheuvart B, Espinoza F, Gillard P, Innis BL, Cervantes Y, Linhares AC, López P, Macías-Parra M, Ortega-Barría E, Richardson V, RiveraMedina DM, Rivera L, Salinas B, Pavía-Ruz N, Salmerón J, Rüttimann R, Tinoco JC, Rubio P, Nuñez E, Guerrero ML, Yarzábal JP, Damaso S, Tornieporth N, Sáez-Llorens X, et al: A short report on highlights of worldwide development of RIX4414: a Latin American experience. Vaccine 2006, 24(18):3784-5.

20. Santos Jl, Martin A, De Leon T, Rivera L, Gaitán ME, Del Rio C, Oselka G, Cervantes $Y$, Rubio P, Clemens SA, de Mendonça JS: DTPW-HB and Hib primary and booster vaccination: combined versus separate administration to Latin American children. Vaccine 2002, 20(1314):1887-93.

21. Lagos R, Valenzuela MT, Levine OS, Losonsky GA, Erazo A, Wasserman SS, Levine MM: Economisation of vaccination against Haemophilus influenzae type b: a randomized trial of immunogenicity of fractional-dose and two-dose regimens. Lancet 1998, 351(9114):1472-6.

22. Anderson EL, Frey S, Geldmacher K, Radley D, Lee A, Donnelly J, Mendelman PM, Dargan JM, Kaplan KM: Safety, tolerability and immunogenicity of low dose Haemophilus influenzae type $b$ conjugated to the outer membrane protein complex of Neisseria meningitidis group b. Paediatr Infect Dis J 2002, 21(4):350-2

23. Campbell JD, Lagos R, Levine MM, Losonsky GA: Standard and alternative regimens of Haemophilus influenzae type $b$ conjugate vaccine (polyribosylribitol phosphate-tetanus toxoid conjugate vaccine) elicit comparable antibody avidities in infants. Pediatr Infect Dis J 2002, 21(9):822-6.

24. Nicol M, Huebner R, Mothupi R, Käyhty H, Mbelle N, Khomo E: Haemophilus influenzae type $b$ conjugate vaccine diluted tenfold in diphtheriatetanus-whole cell pertussis vaccine: a randomized trial. Paediatr Infect Dis J 2002, 2(2):138-41, 1

25. Huebner R, Nicol M, Mothupi R, Käyhty H, Mbelle N, Khomo E, Klugman KP: Dose response of CRM(197) and tetanus toxoid-conjugated Haemophilus influenzae type b vaccines. Vaccine 2004, 23(6):802-6.

26. Tamm E, Veronese A, Contorni M, Meriste S, Nacci P, Viviani S: Doubleblind study comparing the immunogenicity of a licensed DTwPHibCRM197 conjugate vaccine (Quattvaxem ${ }^{\mathrm{T} M}$ ) with three investigational, liquid formulations using lower doses of Hib-CRM197 conjugate. Vaccine 2005, 23(14):1715-9.

27. Halperin SA, Eastwood BJ, Barreto L, Friesen B, Medd L, Meekison W, Guasparini R: Adverse reactions and antibody response to four doses of acellular or whole cell pertussis vaccine combined with diphtheria and tetanus toxoids in the first 19 months of life. Vaccine 1996, 14(8):767-72.

28. Pichichero ME, Deloria MA, Rennels MB, Anderson EL, Edwards KM, Decker MD, Englund JA, Steinhoff MC, Deforest A, Meade BD: A safety and immunogenicity comparison of 12 acellular pertussis vaccines and one whole-cell pertussis vaccine given as a fourth dose in 15- to 20-monthold children. Pediatrics 1997, 100(5):772-88.

\section{Pre-publication history}

The pre-publication history for this paper can be accessed here: http://www.biomedcentral.com/1471-2334/10/297/prepub

doi:10.1186/1471-2334-10-297

Cite this article as: Espinoza et al:: Primary and booster vaccination in

Latin American children with a DTPW-HBV/Hib combination: a

randomized controlled trial. BMC Infectious Diseases 2010 10:297.

\section{Submit your next manuscript to BioMed Central and take full advantage of:}

- Convenient online submission

- Thorough peer review

- No space constraints or color figure charges

- Immediate publication on acceptance

- Inclusion in PubMed, CAS, Scopus and Google Scholar

- Research which is freely available for redistribution
Ciomed Central 